\title{
Eobard Thawne: A Study Case of Main Villains in the Flash Series Season 1
}

\author{
I Komang Sumaryana Putra \\ English Department, Faculty of Arts, Udayana University, Indonesia \\ e-mail: komangsumaryana@gmail.com
}

\begin{abstract}
Every superhero needs a villain. The Flash is an American superhero television series developed by Greg Berlanti, Andrew Kreisberg, and Geoff Johns, airing on The CW. It is based on the DC Comics character Barry Allen / The Flash, a costumed superhero crime-fighter with the power to move at superhuman speeds. In The Flash TV series Season 1, Eobard Thawne is introduced as a scientist from the future; he duplicated the reaction behind Barry Allen/The Flash's powers and learned he would become his own hero's arch-enemy: the ReverseFlash. This study is aimed to identify the methods of characterization used in introducing Eobard Thawne as the main villain, and also analyzing the intrinsic and extrinsic motivations that the main villain character develops. In collecting the data, this study used library research and the data itself was analyzed qualitatively. Finally, the methods of characterization of the main villain character as well as the character's motivations are explained. The character may be seen as simple at first glance, but Eobard Thawne has the components that describe him as evil character; from his characterization in his introduction to the motivations that guide him through each step of the story. Indeed, it is absolute reverse.
\end{abstract}

\section{Keywords}

superhero, main villain character, intrinsic motivation, extrinsic motivation, characterization

\section{Introduction}

As the villain character, Eobard Thawne is presented on The Flash television series in Season 1. A lunatic scientist from the future, he copied the response behind Barry Allen/The Flash's forces and learned he would turn into his very own legend's most outstanding adversary: The Reverse-Flash. This TV Series version is produced by Greg Berlanti, Andrew Kreisberg, and Geoff Johns, airing on The CW network. The Flash is based on the DC Comics character, a costumed hero with the ability to move at superhuman paces. As the villain character, Eobard Thawne has a unique characteristic: the excessive ambition to be the fastest man alive. In Season 1, the plot story is focused on how Eobard went back to past time and try to manipulate Barry and trained him controlled the meta-humans. This study is aimed to identify the methods of characterization used in introducing Eobard Thawne as the main villain, and also analyzing the intrinsic 
and extrinsic motivations that the main villain character develops. In collecting the data, this study used library research and the data itself was analyzed qualitatively. Finally, the methods of characterization of the main villain character as well as the character's motivations are explained. The character may be seen as simple at first glance, but Eobard Thawne has the components that make him into evil character; from his characterization in his introduction to the motivations that guide him through each step of the story.

\section{Theoretical Framework}

In the theory proposed by Reaske in his book "How to Analyze Drama" (1966) he states that there are various devices of characterization in a drama. In his words, a dramatist has a large range of choices for different devices of characterization. Characterization is the literary technique to reveal the nature of a character.

a) The appearance of the character is often described by the playwright in the prologue or in stage directions, the audience then learns what the character looks like and how they are dressed when they walk out on stage.

b) Asides and soliloquies, all further characterization is established by dialogue, the audience learns more about the character through their speech in short asides or longer soliloquies.

c) Dialogue between characters, the audience gets a perception of the character when he talks by himself and when he is the company of other characters and how he presents himself in front of them.

d) Hidden narration is one device that is frequently used, for instance having a character in a play narrate something about another character despite the estimation being truthful or false.

e) Language of any given character is extremely central to his personality attributes, the way a character speaks and expresses themselves should always be our first concern.

f) Character in action, when the playwright chooses to have a character act a certain way and not another, the character is much better understood. Motivation usually translates into action.

In the theory proposed by Ryan and Deci "Intrinsic and Extrinsic Motivations: Classic Definitions and New Directions" Intrinsic motivation remains a vital build, mirroring the normal human penchant to learn and absorb. In any case, extrinsic motivation is contended to differ significantly in its relative selfgovernance and in this way can either reflect outside control or genuine self-guideline. An individual who feels no stimulus or motivation to act is along these lines described as unmotivated, though somebody who is invigorated or initiated toward an end is viewed as persuaded. Outer inspirations will, in general, be pretty much widespread. Inside inspirations are what will individualize the character. Journalists look to continuously uncover the inner inspiration through the occasions of the plot. Want and inspiration is forces of good narrating and are among the most characterizing highlights of artistic fiction. As a general rule, want and inspiration is vital and subject to the various components of fiction; and the longing and inspirations of characters may change, and surely extend in manners that influence them to appear to be changed, with story improvement.

Intrinsic motivation includes participating in conduct since it is specifically fulfilling; basically, playing out an action for the good of a character's own instead of the longing for some outer reward. According to Kieffer in her article "How to Create Character Motivations that will Rivet Your Readers", some intrinsic motivations are:

a) Autonomy; isolation: A character's decision existing or acting separately from others for various reasons such as independence or isolation. Characters strive to achieve self-sufficiency and freedom.

b) Affiliation; conformity: For some characters their motivation is to find security and be part of a bigger circle of people. This way they will achieve cooperation and loyalty from others.

c) Love: A character's motivation to go through their story in the hopes that they earn the love of their friends, lover, or family.

d) Revenge; justice: The character is sworn to take revenge and bring justice to the ones who have wronged him in the course of the plot. For these character, vengeance is the only satisfactory ending.

e) Guilt: After a character has done something regrettable before or during the story they take responsibility and try to find redemption and forgiveness from other characters and themselves. 
f) Identity; self-centeredness: Characters concerned solely or chiefly with their own interests and welfare, or characters who strive to find confidence, self-learning, and self-security.

g) Refrain; strife evasion: Some character's only motivation is to stay clear and avoid the conflicts that surround them either by keeping the peace, escaping or even greeting death with open arms.

h) Spirituality: A character's action that is determined solely on their religious teachings and practices who do not stray from the path chosen from the one they worship. Based on their motivations they can find a cleansed path or experience some kind of transformation to their character.

i) Growth: The motivation of the character to go through the conflict of the story to grow and mature as well as learn valuable knowledge about themselves and their world.

j) Ambition; insecurity/anxiety: A character's motivation to succeed in the fear of losing something or someone greatly important to them in failure.

k) Vindication; rationalization: Proving and showing that the character should not be blamed for a crime, mistake, proving that they are not guilty.

Extrinsic motivation happens when characters are persuaded to play out conduct or take part in an action to gain a reward or maintain a strategic distance from discipline. According to Kieffer, some extrinsic motivations are:

a) Survival/safety: Fear of the world, this includes the motivations the character has for his or her safety such as food, water, or escape from any kind of danger.

b) Physical comfort; gluttony: These are the sentiment of prosperity achieved by interior and ecological conditions that are experienced as pleasant and related with happiness and fulfillment to the character such as shelter, warmth, good food, health.

c) Pleasure; hedonism: Some character's motivations are simply to indulge in their own or others' pleasure and happiness, the belief that pleasure or happiness is the most important goal in life, such as good outcome, romantic/sexual pleasures.

d) Dominance; tyranny: For some their primary motivation is power and coming out on the top, these things include social standing, competition, respect.

e) Acquisitiveness; greed: Characterized by a strong desire to gain and possess material things and desiring to be better than others who already possess such things such as wealth and excellence.

f) Curiosity: The desire to go out in the world for the sake of knowledge and growth, for many characters their motivations are learning, searching, and investigating.

g) Mastery; proficiency: An individual standard, disposition, or rationality that requests flawlessness and rejects anything less. Characters strive to acquire excellence, conquest, discipline, and achievements.

h) Reproduction: A desire to give way to the next generation, characters desire to start a family of their own and raise children.

\section{Results and Discussion}

The Flash first showed on October 7 2014, and finished up on May 19 2015, subsequent to airing 23 scenes for The CW Network. Season 1 of the series pursues Barry Allen, an associate police measurable examiner who was stranded when his dad was erroneously detained following the strange homicide of his mom. The season starts with Allen being struck by lightning amid an exceptional tempest brought about by a particle accelerator blast that washes the city with an unordinary type of radiation. The strike places Allen in a state of unconsciousness for nine months. When he awakens, he rapidly learns he can move at superhuman rates. It's a destiny that likewise happens to others in the wake of the blast and tempest, making a few meta-humans. Allen at that point utilizes his recently discovered capacity to against criminals and go on a chase for his mom's actual executioner. Dr. Harrison Wells is the psyche and cash behind the S.T.A.R. Labs particle accelerator in Central City. In season one he actuates a particle accelerator that discharges dim issue vitality in Central City, executing a few regular people and conceding different people meta-human capacities, including Barry Allen. After nine months, Wells is a hermit and an outcast, bound to a wheelchair. Alongside Cisco Ramon and Caitlin Snow, he builds up Barry's forces as The Flash and tutors him in stretching his speed as far as possible to think of novel answers for bringing down meta-human hoodlums. Be that as it may, Wells has numerous insider facts: 
he is faking loss of motion, has the man-made brainpower Gideon which has data from the future, and is happy to murder to secure his protégé and spread his own tracks. Wells is uncovered to be The ReverseFlash, the strange speedster in a yellow suit who slaughtered Barry's mom in 2000. It is likewise uncovered that Eobard Thawne executed the genuine Harrison Wells, alongside his better half Tess Morgan, and accepted his personality; he coordinated the occasions that would transform Barry into The Flash for his own motivation.

Based on Reaske's theory of the method of characterization, Eobard Thawne's characterization is presented with his actions and interaction with other characters. (1966, p. 46)

a) Dialogue between characters method: the audience gets a perception of the character when he talks by himself and when he is the company of other characters and how he presents himself in front of them. In this case, through Harrison Wells' body, Eobard Thawne talks to his fellows at STAR Labs and develops Barry's power as a speedster.

b) Hidden narration is one device that is frequently used, for instance having a character in a play narrate something about another character despite the estimation being truthful or false. Through Harrison Wells' body, Eobard Thawne has numerous privileged insights: he is faking loss of motion, has the man-made brainpower Gideon which has data from the future, and is eager to execute to secure his protégé and spread his own tracks.

c) Character in action method: when the playwright chooses to have a character act a certain way and not another, the character is much better understood. Motivation usually translates into action. Through Harrison Wells' body, Eobard Thawne is uncovered to be The Reverse-Flash, the secretive speedster in a yellow suit who murdered Barry's mom in 2000. It is likewise uncovered that Eobard Thawne slaughtered the genuine Harrison Wells and accepted his character; he coordinated the occasions that would transform Barry into The Flash for his own plan.

d) Intrinsic motivation includes participating in conduct since it is expressly fulfilling; basically, playing out a movement for the wellbeing of a character's own as opposed to the longing for some outside remuneration. From Flash season 1, we can define Eobard Thawne's intrinsic motivations.

e) Autonomy; isolation: A character's decision existing or acting separately from others for various reasons such as independence or isolation. Eobard Thawne strives to achieve selfsufficiency and freedom, especially in his more youthful years, Eobard was negligible, fairly irascible and temperamental. At the point when Barry Allen discovered Eobard's contempt was on the grounds that he couldn't be much the same as The Flash, Barry communicated nauseate, causing Eobard to snap, shouting that he's "become superior to anything" The Flash, egotistically expressing he's the one individual his adversary can't stop. Discovering that he made such torment and distress The Flash later in his life made Eobard jazzed and glad for his life decisions as The Flash's foe.

f) Identity; self-centeredness: Characters concerned solely or chiefly with their own interests and welfare, or characters who strive to find self-esteem, self-knowledge, and self-protection. Although polite, Eobard is also shown to be rather arrogant, self-righteous, overconfident, somewhat cruel and sadistic. These traits were evident during his first encounter with the Flash with Eobard believing the Flash couldn't keep up with him. Despite his superior speed, Eobard gets outsmarted, beaten unconscious and imprisoned.

g) Growth: The motivation of the character to go through the conflict of the story to grow and mature as well as learn valuable knowledge about themselves and their world. In his younger years, Eobard had a scientific obsession with the Flash to the point where he reversed engineered the reaction which his idol's powers to give himself the ability to access the Speed Force. This obsession led Eobard to study the Speed Force and experiment its potential after gaining his powers. This eventually led him to develop technologies that not only help enhance his powers but also against other speedsters who oppose him which led him. Through his experiments, he was eventually able to discover his ability to time travel and began abusing this ability to the point where he was mostly unaffected by the changes he made in the past.

h) Ambition; insecurity/anxiety: A character's motivation to succeed in the fear of losing something or someone greatly important to them in failure. After learning the Flash's secret identity, Eobard traveled back in time to kill Barry as a child to erase his foe from existence but was thwarted by the Flash of a later time who brought the younger Barry to safety. An enraged Eobard then killed Nora Allen and framed Henry Allen for the crime instead. However, Eobard lost his connection to the Speed Force, becoming trapped in the early 
twenty-first century. Realizing Barry was the only way to return to his time, Eobard killed Dr. Harrison Wells, the director of S.T.A.R. Labs, and assumed his identity to push through for the creation of a particle accelerator to ensure that Barry would become the Flash. Posing as Wells, Eobard tutored The Flash and turned into the pioneer of a group he gathered to stop the meta-human dangers, to expand his protégé's speed so that Eobard could utilize the saint's association with the Speed-Force to come back to his own time. He has a great ambition to become the fastest man alive.

Extrinsic motivation happens when characters are spurred to play out conduct or participate in an action to procure a reward or keep away from discipline. Eobard Thawne's extrinsic motivations are:

a) Survival/safety: Fear of the world, this includes the motivations the character has for his or her safety such as food, water, or escape from any kind of danger. Eobard has huge information and capability in different fields of science, most noticeably appeared from his effective replication of The Flash's mishap to recreate his previous symbol/future chief rivals' forces for himself. He has eminent learning of meta-human organic chemistry and sub-atomic structure, making a biomolecular enhancer. However, he fears that he can't reach his ambition to become the best speedster.

b) Dominance; tyranny: For some their primary motivation is power and coming out on the top, these things include social standing, competition, respect. Eobard is appeared to rejoice in the light of ridiculing his adversaries for their own behavior's aftermath, showed when Harry Wells came to free him to be sent back to his own time in order to fix the timetable harm. Eobard additionally will legitimize his killings by expressing that every one of those whom he had killed had just been dead for a considerable length of time from his point of view, (for example, Nora and Tess Morgan), not thinking about his unfortunate casualties or perceiving how his demonstrations are hurting the course of events.

c) Acquisitiveness; greed: Characterized by a strong desire to gain and possess material things and desiring to be better than others who already possess such things such as wealth and excellence. Because of the colossal measures of Speed-Force vitality in his body, Eobard shows a level of superhuman quality, applying barbaric measures of power without utilizing his speed. To fulfill his ambition, he develops the S.T.A.R. Labs particle-accelerator in Central City through Harrison Wells' body.

d) Mastery; compulsiveness: An individual standard, the frame of mind, or reasoning that requests flawlessness and rejects anything less. Characters strive to acquire excellence, conquest, discipline, and achievements. Utilizing the Speed Force, speedsters, for example, The Reverse-Flash can direct chrono-kinesis, or fleeting control, which enables him to go all through time. He has appeared inside and out learning and comprehension of time-traveling. Eobard is an incredible strategist, as to prove by him concocting plans to help Barry Allen rout the meta-people. He figured out how to for about a year to keep Team Flash from making sense of what he is The Reverse-Flash. Eobard is additionally an incredible agent, as to prove by the pivotal job he played in Team Flash and making the particle-accelerator and ran S.T.A.R. Labs effectively for a long time until the particle-accelerator blast occurrence made the organization shut down. He is also skilled with contingency plans.

\section{Conclusions}

From the findings and analysis, Eobard Thawne's characterization is presented with his actions and interaction with other characters, i.e. dialogue between characters method, hidden narration, and character in an action method. Eobard is very powerful at beguiling individuals, ready to work intimately with Team Flash for a considerable length of time as Harrison Wells without them knowing who he truly is. From Flash season 1, we can define Eobard Thawne's intrinsic motivations, such as autonomy/ isolation, identity/self-centeredness, growth and ambition/insecurity/anxiety. Another eminent identity attribute is his profound and unquenchable contempt for The Flash. Eobard conceded that he used to be an immense devotee of The Flash, venturing to discover how his saint became and how to end up like the man, notwithstanding prevailing with regards to increasing super-speed himself. Eobard also has huge learning and capability in different fields of science, makes the vast majority of his extrinsic motivation: survival/safety, dominance/ tyranny, acquisitiveness/greed, and mastery/perfectionism. However, the majority of Eobard's arrangements are thwarted, and he is eradicated from presence when his 
predecessor Eddie Thawne ends it all. In the occasion of his death and his arrangement to come back to his very own time were to come up short, Eobard made a video admission to Nora's homicide for Henry's opportunity.

\section{References}

1. Kieffer, K. (2015). How to Create Character Motivations that will Rivet Your Readers. Retrieved from http://www.shesnovel.com

2. Reaske. C. (1966). How to Analyze Drama. Oxford: Monarch Press. p. 46

3. Ryan, R.M \& Deci, E. L (2000). "Intrinsic and Extrinsic Motivations: Classic Definitions and New Directions.” Contemporary Educational Psychology. Vol 25 (1) pp. 54-67 